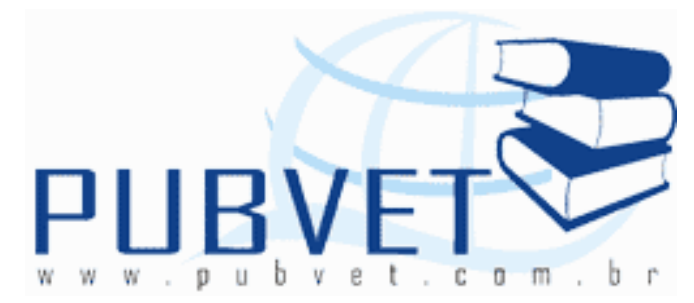

PUBVET, Publicações em Medicina Veterinária e Zootecnia.

\title{
Avaliação do desempenho de bovinos de corte mestiços confinados em piquetes com sombrite e sem sombrite
}

Rodrigo Zaiden Taveira1*; Luciana Rodrigues Fonseca3 ; Osvaldo José da Silveira Neto ${ }^{2}$; Alliny das Graças Amaral ${ }^{1}$; Jean Sardinha de Almeida ${ }^{4}$;

${ }^{1}$ Doutor, Docente do Curso de Zootecnia. Universidade Estadual de Goiás, São Luís de Montes Belos, Brasil.*rodrigo.zaiden@ueg.br

2Mestre, Docente do Curso de Zootecnia, Universidade Estadual de Goiás, São Luís de Montes Belos, Brasil.

3Zootecnista, Universidade Estadual de Goiás, São Luís de Montes Belos, Brasil.

${ }^{4}$ Acadêmico, Curso de Zootecnia, Universidade Estadual de Goiás, São Luís de Montes Belos, Brasil.

\section{Resumo}

Este trabalho teve como objetivo avaliar as características de ganho em peso diário, peso de carcaça, consumo de matéria seca, peso de saída e conversão alimentar de animais mestiços confinados em piquetes com e sem sombrite. Os dados utilizados nesse estudo foram provenientes de um confinamento de bovinos de corte localizado no município de Aruanã, estado de Goiás. Foram confinados 16.000 mil bovinos machos mestiços em torno de 24 meses de idade. A sombra dos piquetes era constituída por uma cobertura de tela de polietileno com $70 \%$ de proteção contra raios solares. O período de 
confinamento total foi de 90 dias, sendo 07 dias de adaptação. Animais confinados em piquetes com sombrite apresentaram maior ganho em peso diário $(1,80 \mathrm{Kg})$ em relação aos animais sem sombrite $(1,61 \mathrm{Kg})$. Para as características analisadas como peso de carcaça, consumo de matéria seca e conversão alimentar não foram observadas diferenças significativas entre os dois tratamentos. Pode ser observado que a disponibilidade do sombrite influenciou no desempenho dos animais mestiços confinados em piquetes com sombrite.

Palavras-chave: abate, adaptação, ganho em peso.

\section{Performance evaluation of crossbred beef cattle kept in feedlot with and without shadows}

\section{Abstract}

The aim of this paper was to evaluate the traits of daily weight gain, carcass weight, dry matter intake, final weight and feed conversion of crossbred bovines kept in feedlot with and without shadow. The data used in this study were provided from one feedlot located in Aruanã city, Goiás state. Were confined 16,000 thousand crossbred males bovines around 24 months of age. The shadows used were consisted of polyethylene screen coverage with $70 \%$ protection against solar rays. The total confinement period was 90 days, being 07 days of adaptation. Animal kept in feedlot with shadows showed highest daily gain $(1.80 \mathrm{Kg})$ compared with the animal without shadow $(1.61 \mathrm{~kg})$. Considering the evaluate traits as carcass weight, dry matter intake and alimentary conversion does not showed significative differences between the two treatments. Could be observed that the shadows influences the performance of crossbred animals kept in pasture with shadows.

Keywords: slaughter, adaptation, weight gain. 


\section{INTRODUÇÃO}

A adequada manutenção do ambiente térmico traz benefícios à produção animal, aumentando a produtividade e a eficiência no consumo dos alimentos. Dentre os métodos usados para promover melhorias no ambiente, pode-se citar o sombreamento nas pastagens, o confinamento e a oferta adequada de água (SILVA, 2000).

O sombreamento é benéfico e recomendado em climas quentes, pois favorece a perda de calor e a regulação da temperatura corporal. Os animais procuram as sombras nas horas mais quentes do dia e, se este recurso estiver à disposição, suas necessidades serão atendidas, devendo ter sombra suficiente para abrigar todos os animais ao mesmo tempo e a qualquer hora do dia (PARANHOS DA COSTA, 2000).

Nesse sentido objetivou-se avaliar as variáveis de ganho em peso diário, peso de carcaça, consumo de matéria seca, peso de saída e conversão alimentar de bovinos mestiços confinados em piquetes com e sem sombrite, afim de perceber a influência do melhor conforto térmico sobre as variáveis de desempenho.

\section{MATERIAL E MÉTODOS}

O experimento foi realizado em um confinamento de bovinos de corte, localizado no município de Aruanã, estado de Goiás, no período de 11 de julho á 23 de setembro de 2011. Foram confinados 16.000 mil bovinos machos mestiços com 24 meses de idade, os quais foram aleatoriamente distribuídos em 80 piquetes, sendo $40 \mathrm{com}$ sombrite e $40 \mathrm{sem}$ sombrite. Cada piquete possuía 200 animais, com área de $70 \mathrm{~m} \times 50 \mathrm{~m}\left(17,5 \mathrm{~m}^{2} / \mathrm{cab}\right)$, com bebedouros de alvenaria com bóia com capacidade de 2.000 litros e um cocho de concreto com $70 \mathrm{~m}$ (35 cm/cab) para o fornecimento de alimento. O sombrite era constituído por uma cobertura de tela de polietileno com $70 \%$ de proteção contra raios solares, possuindo 70 metros de comprimento, 3,5 
metros de altura e 5 metros de largura, com área de $4 \mathrm{~m}^{2} /$ boi. 0 período de confinamento total foi de 90 dias, sendo 07 dias de adaptação.

Os animais receberam água á vontade e foram alimentados com silagens do gênero Panicum maximum cvs. capim-mombaça e capim-tanzânia, bagaço de cana-de-açúcar como fonte de volumoso e farelo de soja, polpa cítrica peletizada, melaço de soja, milho triturado, caroço de algodão e torta de algodão como fonte de concentrado, núcleo e gordura protegida. A relação volumoso:concentrado dessas dietas foram: adaptação 35:65; crescimento 20:80; terminação $12: 88$.

As variáveis avaliadas nos bovinos mestiços foram: Ganho em peso diário (Kg/cab./dia); Peso da Carcaça ( $\mathrm{Kg})$; Consumo de matéria seca (Kg/dia); Peso de saída (Kg) e Conversão alimentar (Kg/MS/Kg/PV).

Os dados foram analisados pelo programa estatístico SAS e as médias comparadas por meio do teste de Student $(P<0,05)$.

\section{RESULTADOS E DISCUSSÃo}

Pode ser observado na tabela 3 os dados referentes às características de desempenho de bovinos mestiços confinados com e sem sombrite.

Os animais confinados em piquetes com sombrite apresentaram maior ganho em peso diário em relação aos animais sem sombrite. SILVA et al. (2008), comprovou em seu experimento com novilhos mestiços que o sombreamento pode influenciar no ganho em peso, proporcionando superioridade de ganho em peso de $1,691 \mathrm{~kg} /$ dia aos animais com acesso a sombra.

Segundo CHIQUITELLI NETO (2001), o calor causa estresse nos animais prejudicando o bem-estar, diminuindo o ganho em peso, causando redução no consumo de alimentos, proporcionando menor grau de acabamento nas carcaças de animais confinados. Por isso torna-se importante a disposição de sombras aos animais para melhorar o bem-estar e seu desempenho. 
Tabela 3. Médias e desvios padrões do ganho de peso médio diário (GMD), peso de saída (PS), peso de carcaça (PC), consumo de matéria seca (CMS) e conversão alimentar (CA) dos animais confinados em piquetes com sombrite e sem sombrite.

\begin{tabular}{ccc}
\hline & \multicolumn{2}{c}{ Animais Mestiços } \\
Características & Com Sombrite & Sem Sombrite \\
\hline GMD & $1,80 \pm 0,14 \mathrm{a}$ & $1,61 \pm 0,20 \mathrm{~b}$ \\
Peso de Saída $(\mathrm{Kg})$ & $517,53 \pm 58,30 \mathrm{a}$ & $504,52 \pm 51,01 \mathrm{~b}$ \\
Peso da Carcaça $(\mathrm{Kg})$ & $290,46 \pm 28,97^{\mathrm{ns}}$ & $288,17 \pm 39,02^{\mathrm{ns}}$ \\
Consumo MS/kg/dia & $10,79 \pm 1,01^{\mathrm{ns}}$ & $10,50 \pm 1,20^{\mathrm{ns}}$ \\
CA $(\mathrm{Kg} / \mathrm{MS} / \mathrm{Kg} / \mathrm{PV})$ & $6,72 \pm 1,14^{\mathrm{ns}}$ & $6,37 \pm 0,53^{\mathrm{ns}}$ \\
\hline
\end{tabular}

a,b características seguidas de letras diferentes na mesma linha diferem entre pelo teste de Student $(p<0,05)$. ns não significativo pelo teste de Student $(p>0,05)$.

O peso de saída dos animais confinados com acesso a sombra foi superior aos animais que não tinham acesso ao ambiente sombreado, sendo observada diferença significativa $(P<0,05)$, apresentando superioridade de $13,01 \mathrm{Kg}$ para animais com sombrite. MARQUES et al. (2007), confirmaram o benefício do sombreamento, obtendo uma média superior de $7,5 \mathrm{Kg}$ no peso final para animais mantidos em piquetes com sombra.

Para as características analisadas como peso de carcaça, consumo de matéria seca e conversão alimentar não foram observadas diferenças significativas entre os dois tratamentos.

\section{CONCLUSÃO}

O uso do sombrite no confinamento incrementou o desempenho dos bovinos mestiços, os quais aumentaram sua produtividade em ambiente de menor estresse térmico. 


\section{REFERÊNCIAS}

CHIQUITELLI NETO, M. Efeito do sombreamento natural sobre o ganho de peso de novilhas confinadas. In: ZOOTEC, 2001; CONGRESSO BRASILEIRO DE ZOOTECNIA, 21.; CONGRESSO INTERNACIONAL, 3., 2001, Goiânia, GO. Anais... p.

FORTES, Gitânio. O boi exige bem-estar para produzir mais. DBO, São Paulo, v.21, n.262, 2002.p.138-142.

MAC-LEAN, P. A. B. Sombra artificial e método de fornecimento de concentrado no comportamento e desempenho de bezerros desmamados. 2008. 29p. Dissertação (Mestrado em Zootecnia)-Universidade Estadual de Maringá/PR, Maringá.

MARQUES, J. A. et al. Comportamento ingestivo de tourinhos confinados com ou sem acesso à sombra. Revista Campo Digit@I, Campo Mourão, v.2, n.1, p.43-49, 2007.

PARANHOS DA COSTA, Mateus José Rodrigues. Ambiência na produção de bovinos de corte a pasto. In: ENCONTRO ANUAL DE ETOLOGIA, 18. 2000. Florianópolis: SC.

Anais.....Florianópolis: Sociedade Brasileira de Etologia, 2000. p. 1-15.

SILVA, R. M. et al. Influência do sombreamento sobre o desempenho de novilhos mestiços zebuínos confinados. 2008. Disponível em: http://www.abz.org.br. Acessado em: 10 de outubro de 2011.

SILVIA, R. G. Introdução à bioclimatologia animal. São Paulo: Editora Nobel, 2000. 286 p. 